\title{
The courage to be vulnerable: exploring experiences of peer and self-assessment of teaching in nursing education
}

This article was published in the following Dove Press journal:

Nursing: Research and Reviews

7 February 2017

Number of times this article has been viewed

\section{Jennifer D Tanner \\ Patricia A Rosenau \\ Tracey L Clancy \\ Gayle E Rutherford}

Faculty of Nursing, University of Calgary, Calgary, AB, Canada
Correspondence: Jennifer D Tanner Faculty of Nursing, University of Calgary, 2500 University Drive NW, Calgary, AB, Canada T2L IN4

Tel + I 4032206262

Fax +I 4032844803

Email jddellai@ucalgary.ca
Background: Within academia, more than one measure of assessment is required to ensure teaching success and ongoing teaching development. Peer assessment of teaching is one of the methods that can benefit teaching development; however, there is currently a lack of nursing research literature regarding the processes, outcomes, and use of self-reflection in the peer assessment process. In the spring and summer of 2015, the development and implementation of a tailored pilot project of peer and self-assessment of teaching occurred within an undergraduate nursing program at a Western Canadian university. The overarching philosophy of the pilot project of peer and self assessment was one of using peer to peer developmental feedback as a means of creating a community of support for professional teaching development. The study reported on in this paper is an initial step in addressing a lack of research literature within the field of nursing to support the practice of peer assessment of teaching as a sustainable and effective means of offering teaching development support. Purpose: The aim of this study was to explore and describe the experiences of teaching faculty participants in the pilot project of peer and self-assessment of teaching.

Methods: A qualitative descriptive design was employed to explore the experiences of pilot participants. Focus group discussions and individual interviews were used to gather data.

Participants: A total of 12 nursing educators involved in the pilot project participated in the study.

Findings: Conventional content analysis of the combined data rendered themes around vulnerability and the influence and importance of establishing trust in selecting a partner, making teaching public, improving teaching practice, and maintaining accountability and responsibility. Conclusion: Peer and self-assessment of teaching has the potential to benefit professional teaching development in nursing education. Both peers within a peer and self-assessment partnership can experience feelings of vulnerability. Having the courage to be vulnerable or identifying and overcoming vulnerabilities and establishing trust with a teaching colleague can result in mutual learning, can benefit individual and team growth, and can enhance accountability to the undergraduate nursing curriculum and student learning.

Keywords: professional development, qualitative study, nursing faculty, self-reflection, peer assessment

\section{Introduction}

Successful teaching is inarguably a common goal of educators, and it is one that is complex and challenging to measure. In nursing education, the current gold standard approach for measuring teaching success is through the use of student evaluations of teaching. ${ }^{1}$ While student evaluations of teaching are widely used and, for the most part, recognized as useful measures of teaching competence, solely relying on one form of 
feedback can have a negative impact on teaching development and the quality of education delivered to students. ${ }^{2}$ Nursing as a profession remains under pressure to find solutions for the continued shortage of nurses as well as the looming shortage of qualified faculty to teach and graduate a sustainable professional workforce. ${ }^{3,4}$ This, compounded with a dearth of research related to nursing education delivery, lack of training for those in teaching roles, and variable support for the ongoing development of teaching practices and scholarship, ${ }^{5}$ highlights the pressing need for innovation and change to support and maintain a committed and satisfied team of educators.

One mechanism that is recognized within academia as a successful means of offering additional tools to determine areas of teaching strength and areas in need of development is the use of a program of peer assessment or review of teaching. ${ }^{6-8}$ There is, however, a lack of research literature within the field of nursing to support the practice of peer assessment of teaching as a sustainable and effective means of offering teaching development support. Feelings of threat are often associated with peer assessment processes that are used for performance evaluation or promotional purposes. ${ }^{9}$ These factors, along with the potential benefit but under studied use of self-reflection as integrated steps in the peer assessment process, and the desire and motivation of teaching faculty for a more developmental and supportive approach, led to the creation of a tailored pilot project of peer and self-assessment of teaching. The purpose of this article was to both describe the pilot project that took place in an undergraduate nursing program at a Western Canadian university and explore the experiences of participants.

The pilot initiative of peer and self-assessment of teaching was codeveloped by a team of educators of various ranks, a graduate student, and pilot participants. The emphasis of the initiative was on a full circle model of teaching assessment that begins and ends with the individual, with a strong focus on self-reflection on the part of the faculty member at the receiving end of peer feedback. An overarching philosophy of peers as equals with the overall goal of creating a community of support for teaching development shaped the construction of the initiative. In this article, we report on an evaluation of the pilot project using qualitative descriptive ${ }^{10}$ methodology to explore the experiences of pilot participants. The findings of this study are supportive of the potential benefit of peer and self-assessment on professional teaching development in nursing education. This study is an initial step in a longer-term vision of examining the outcomes of peer and self-assessment of teaching which are currently lacking in the literature.

\section{Background}

Student evaluations of teaching, while commonly used as the only method of providing feedback to teaching faculty, are not without their challenges. ${ }^{2,11-13}$ There is an abundance of literature that discusses issues such as rating teachers more favorably when higher grades are assigned, the lack of constructive comments provided due to the anonymous nature of the tools, and the stress and confusion that can result from poor evaluations. ${ }^{2,4,11,12}$ Negative student evaluations, along with the isolation that can sometimes occur within teaching, are shown to directly impact educators' role satisfaction, teaching development, and ultimately the quality of education provided to students, ${ }^{2,4,14}$ which indicates the need for further measures of teaching success.

Peer assessment, also known as peer review, peer observation, and teaching consultation, is a tool often used within faculties of higher education such as science, law, and education as a means of offering either a summative review of teaching for standardization and accreditation purposes or as a tool for offering teaching development support. ${ }^{14,15}$ There is variability in the methods in which peer assessment is conducted that can range from mandatory programs utilizing peers selected by administration and trained in the evaluation process to self-selecting and volunteering to participate in peer assessment. ${ }^{7,13,16}$ Regardless of the form it takes, most articles related to peer assessment indicate the positive benefits to educators. These benefits include the alteration of teaching practices with a focus on varying techniques and learner centeredness, increased teaching confidence, the potential for improved student learning, and enhanced collegiality. ${ }^{6,8}$ Through initial discussions with members of a nursing faculty at a Western Canadian university, it was recognized that there was a desire for more support for nursing educators with less of a focus on evaluation and more on providing tools that could be used in addition to student evaluations for the identification of teaching strengths and areas for development. Although the concept is not new, ${ }^{17}$ within the field of nursing, there is a lack of published research literature related to peer and self-assessment of teaching.

What is known about peer assessment in nursing is that, most commonly, faculties tend to adopt or develop a program of peer assessment in some form either as a new initiative within a faculty that is unfamiliar with the process ${ }^{17-20}$ or as part of a university-wide initiative aimed at improving scholarship and quality of teaching through evaluation. ${ }^{9,21,22}$ While there is some consistency in the actual process of peer assessment, it seems to be common that most programs are developed and tailored to a specific setting. ${ }^{17,18,22,23} \mathrm{~A}$ tailored 
project of peer assessment is of benefit in faculties of nursing due to the variations in teaching environments and therefore approaches and philosophical goals.

Depending on the intention of the process, peer assessment is commonly seen as a threat by teaching faculty members, no matter the discipline..$^{9,18,19,24,25}$ Anxiety and stress are noted to be common feelings among teaching faculty, where the process of peer assessment is meant for evaluation purposes and is mandatory, and where those involved are unable to choose a peer to be their assessor., ${ }^{9,18}$ Peer assessment processes, where the program is voluntary and where faculty members are able to self-select their peer assessor, reported easing of such feelings of threat and anxiety, ${ }^{17,19,21,22,25}$ lending to the support of a program that is meant to be developmental rather than evaluative in nature.

Common in the literature is the need for some structure to the process. ${ }^{9,19,26}$ Peer assessment processes tend to be better received by teaching faculty when there is an element of training involved. ${ }^{9}$ While a voluntary nature with the ability to self-select a peer observer tends to be the preferred approach, without a structured approach to providing feedback, there can be the potential for a biased or one-sided review. ${ }^{19} \mathrm{Bal}-$ anced critiques are necessary to allow for reflection and the identification of development needs or to provide a full picture of teaching ability for evaluation purposes. ${ }^{26}$

Educators improve their teaching through reflection. ${ }^{9}$ While most initiatives and studies indicate that reflection on teaching by both members of an observation pair is a benefit of the process, ${ }^{9,19,20,22,27,28}$ there is little published in nursing regarding the possible benefits of self-reflection as actual steps in the process. Including self-reflection as part of the process for a profession, such as nursing that already uses reflection as an ingrained element of practice, would be key to meeting the needs of nursing faculty. Encouraging self-reflection prior to and following the process could also add an element of ownership to those receiving feedback and maintain the philosophy of support for teaching development in nursing underlying the initiative described in this article.

\section{Peer and self-assessment of teaching: description of the pilot}

Following the review of the literature, we elicited key stakeholder involvement, which included nursing educators of all ranks (clinical nursing instructors, course instructors, senior instructors, professoriate, and nursing administration). Through consultative stakeholder processes, we created a full circle model for peer and self-assessment as shown in Figure 1.

The process involved peers as equals, where years of experience did not impact who could act as an observer. As the process focused on teaching development, the philosophy was that all educators, no matter what their rank, would have something to offer fellow faculty in terms of feedback on teaching. Therefore, the pilot also included the provision of development opportunities in areas such as how to provide feedback to peers, how to maintain the philosophi-

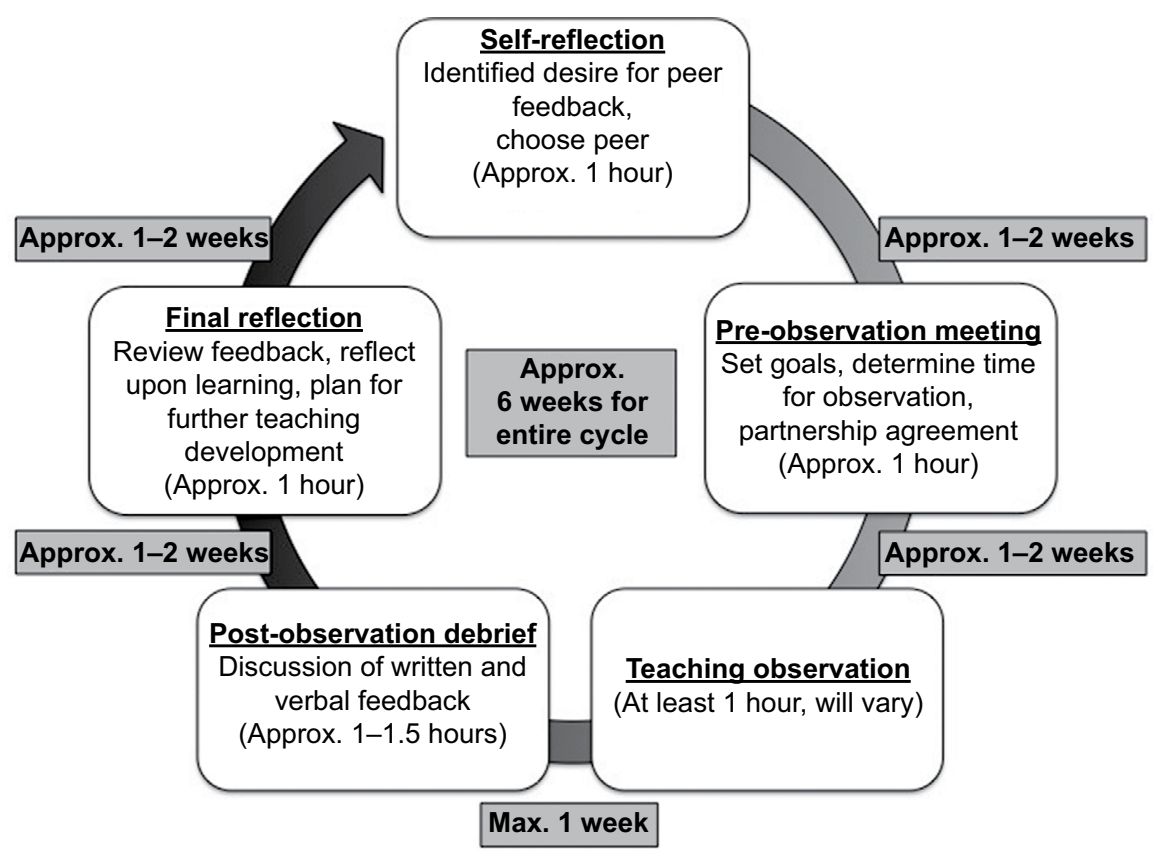

Figure I Peer and self-assessment of teaching process cycle.

Abbreviations: Approx., approximately; Max., maximum. 
cal underpinnings of the process, and the codevelopment of tools for observation, reflection, and feedback provision to assist in the process. Through a voluntary process, nursing educators selected partners from those involved in the pilot development workshops. We limited partner selection to pilot participants to maintain the philosophy of peers as equals with a focus on the development and not the evaluation of peers. Following pairing, participants engaged in independent self-reflection to determine the areas of strength and areas in need of individual professional development. The initial self-reflection was followed by a face-to-face discussion between pair partners to determine the goals of the process and to select any tools to be used for observation and feedback provision. We provided the partners with a handbook that contained guides for observation and feedback, and strove to act as a reminder at each stage in the process that the intent was to be a supportive developmental process. Observation then occurred followed by the provision of verbal and written feedback to the peer who was observed. Finally, to complete the full circle model, the peer on the receiving end of feedback provision was to engage in a final self-reflection about the entire process and what the feedback received meant to the individual.

We provided evaluation tools to participants to complete following each step of the cycle. We used the evaluation tools to ensure that any required adaptations for each portion of the process not only followed evidence-informed practice but also suited the needs of the faculty to maintain the philosophy of creating a community of support for teaching development. While it could be argued that students should be involved as stakeholders as teaching impacts student learning, the sense within the faculty was one in which educators were looking for a process that was separate from the student feedback system. Therefore, students were excluded in the development phase to aid in the creation of a sense of collegial trust.

The pilot project of peer and self-assessment of teaching within the undergraduate nursing program began with training for participants in May 2015. Participants volunteered for the initiative and chose their own peer assessment partners. Completion of the peer and self-assessment process cycle, with the potential completion of a reciprocal cycle, occurred over the spring and summer semesters of 2015.

\section{Curricular context of the pilot/study environment}

An important background element of the pilot and study environment is the recent implementation of a redesigned undergraduate nursing curriculum. With the goal of improving student learning and meeting the educational needs of new nurses entering into a changing, dynamic, and challenging health care environment, nursing faculty undertook an innovative curriculum redesign as a means of moving away from a heavy focus on content and silo-based teaching and learning and focusing more on an integrative approach. ${ }^{29}$ Curriculum redesign involved understanding and combining key elements of complexity science or the adaptive influence of individual parts on the greater system such as the influence of nurses and the profession of nursing on the greater health care system, along with critical attributes of professional nursing practice to meet the practice standards outlined by regulatory bodies. ${ }^{29,30}$ The goals of the new curriculum led to a change in the delivery of educational content with a stronger focus on the context of nursing practice and integrative learning to bridge the gap between theory and practical learning environments. ${ }^{29}$ From a faculty perspective, this change required a more learner-centered pedagogical approach and a strong focus on teaching as part of a team where each course of instruction is linked to the whole of the curriculum. ${ }^{29}$ Team-based teaching and learning is an integral part of the teaching and learning approach of the faculty and forms the foundation of this study reported on in this paper.

\section{Purpose}

The aim of this study was to explore and describe the experiences of pilot participants in the peer and self-assessment of teaching initiative described in the Background section of this paper.

\section{Methods}

A descriptive qualitative ${ }^{10}$ methodology was used to explore and describe the experiences of participants.

The research question that guided the study was: what is the experience of nursing educators who participate in the pilot project of peer and self-assessment of teaching and how does their role of peer assessor and/or being observed impact their professional teaching development?

\section{Participants}

Following approval from the Conjoint Health Research Ethics Board (CHREB), we invited faculty members who participated in the pilot initiative to participate in the study. Study participants did not necessarily need to have completed a cycle of the peer and self-assessment process but did have to be involved in the information and orientation workshops provided as part of the pilot development process. We notified participants of the voluntary nature of the study and obtained 
their written informed consent after ensuring that their names and any other identifying data would not be shared outside of the focus group participants. Following recruitment, 12 participants agreed to be a part of the study. The sample consisted of eight instructor-level faculty members, three senior instructor-level faculty members, and one associate professor-level faculty member. Four participants were also members of the pilot project advisory/development committee. Four participants or two pairs completed the full peer and self-assessment process cycle with reciprocal cycles in which peer partner roles were reversed. One participant was involved from an administrative perspective and therefore, did not participate in a peer and self-assessment process cycle. The remaining participants were each at different stages of the process cycle with two participants having engaged only in the peer and self-assessment development workshops offered as part of the pilot.

\section{Data collection}

Data collection involved two focus group discussions at the university where the study occurred. The focus groups consisted of five participants in the first, and three in the second, and lasted for 1 hour each. Focus groups comprised of both peer assessors and those observed. We interviewed four individual participants who were either unable to attend one of the two focus groups, or were more comfortable with a one-on-one interview style. We audio recorded each focus group and individual interview.

\section{Data analysis}

The principal investigator, coinvestigators, and graduate student conducted the data analysis. We used conventional content analysis, as the goal was to understand and describe the experiences of peer and self-assessment. ${ }^{31}$ Conventional content analysis is appropriate when there are limited existing research data or knowledge regarding a subject, as is the case of peer and self-assessment of teaching in nursing research literature. ${ }^{31}$ Analysis is an iterative process and, therefore, began during the focus groups/interviews themselves and continued throughout the subsequent reviews of the transcripts. A professional transcriptionist and the first author transcribed the audio recordings of focus groups and interviews verbatim followed by iterative reading and summarizing of the informational content of the transcripts. ${ }^{32-34}$ The first author made notes after an initial review of transcripts highlighting first impressions and beginning the initial analysis. ${ }^{31}$ The purpose of conventional content analysis was to describe the phenomenon and not to generate theory; therefore, rather than using preconceived categories, the research team familiarized themselves with the data through immersion, and through this themes were identified. ${ }^{10,31}$ The research team discussed and agreed upon the identified themes

\section{Findings}

From the focus group discussions and individual interviews, an overarching theme of vulnerability emerged. Vulnerability was experienced and had an influence upon all aspects related to the process of peer and self-assessment of teaching. Key to the understanding of vulnerability and easing of feelings of vulnerability was the establishment of courage within individuals and trust between partners. In the following sections, we explore four subthemes, namely selecting a partner, making teaching public, improving teaching practice, and accountability and responsibility supported with the integration of quotes from the transcribed interviews to highlight vulnerability and the influence of courage and trust.

\section{Selecting a partner}

Participants experienced vulnerability in the process of selecting a partner to pair with for the purposes of observing and providing feedback on teaching practices. Several factors influenced their partner selection. As one participant noted, she preferred to pair with someone with whom she did not regularly teach as a means of observing a different teaching style from her own. Another participant discussed how she and her partner had chosen each other because they were looking forward to observing content taught to students in different years of the undergraduate curriculum. One participant noted that it would be a good idea to choose a partner with a similar teaching style or philosophy for the first time completing a peer assessment process to ease feelings of nervousness or vulnerability, and then choosing someone different for subsequent cycles.

While it was common for participants who self-identified as novice educators to place value on choosing a partner with more years of teaching experience, feelings of vulnerability emerged around what they would be able to offer to the relationship with their more experienced partners. This was described by one participant who said, "The vulnerability is that yes she's been teaching for quite some time, I'm afraid on my part, like what have I got to offer?" Another novice educator found it intimidating to think about giving someone with more experience feedback on how to improve. This vulnerability, however, was not limited to novice educators. Partners with more years of teaching experience also felt vulnerable after observing their peers, in particular feeling 
that they would need to improve their own teaching processes before being observed.

No matter the reason for selecting a peer partner, trust and support were key topics that stood out in both the focus group discussions and interviews. As described by one participant:

[...] we just really trusted and had a good rapport with each other and were just happy to have the opportunity to have a window into what it looked like to see each other teach.

Forums to discuss and share feelings of vulnerability, goals, and expectations were key elements in easing feelings of nervousness or vulnerability and establishing trust. In particular, the premeeting discussions helped to ease the sense of vulnerability in the partnerships. With established trust, feelings of vulnerability were lessened as described by one participant: "I kind of got that feeling, regardless of how I do, she's a safety net, she's not going to be watching me drown."

\section{Making teaching public}

Vulnerability was created through the public nature of the observation that occurs in peer and self-assessment of teaching. This vulnerability was associated with peer observation of teaching because the provision of feedback is uncommon in nursing education. Even in forums where teaching is more public, such as in a co-teaching approach, discussing teaching strategies or offering peer feedback is not common, "because if somebody's not asking for your opinion you don't always want to provide it."

In addition, participant's perceptions of their relationships with their students created vulnerability around being observed. One participant described how tensions with students halted the process of peer and self-assessment for her and her partner:

[...] she had some hesitations as to the dynamics of the class that she was teaching and felt that it wasn't a good reflection of what her teaching would look like and asked me not to come.

Participants believed that integrating a process of peer and self-assessment of teaching into professional development strategies for nursing educators resulted in the creation of a more public approach to teaching. Participants described how historically there was a lack of sharing of teaching strategies in nursing education and processes such as the pilot, along with influences of the new integrated curriculum, required a different, more open approach: "I think it, [the process] really asks us to make our teaching public in that sense because when we share the curriculum, we share assessment strategies." Through the creation of a more public approach, participants also described how this method of teaching would parallel the way in which nurses work in a clinical setting. Participants viewed the practice of nursing as a public endeavor, and the adoption of a more public approach to teaching in a classroom setting could potentially result in the easing of feelings of vulnerability associated with the lack of exposure to peer observation and feedback provision:

When we practice nursing it's in a public domain [...] there's caregivers coming in and out $[. .$.$] you have to answer ques-$ tions and give justification for the care you're giving, but yet when you teach it's often not like that.

An historical lack of sharing and the transition from that of an expert clinical practitioner to a novice educator can also result in feelings of uncertainty around individual teaching skill and vulnerability or nervousness around opening up and sharing such feelings to develop as an educator:

It's a very very vulnerable place to be, to express that you're really a novice teacher $[. .$.$] but if you are brand new you have$ something to prove. The expectation is because you're hired for this expert knowledge that you're going to transition.

While it was agreed that engagement in professional teaching development strategies such as peer and self-assessment could lead to a more public or open approach to teaching, vulnerability still remains in the required willingness of educators to expose their practices and share their vulnerabilities. This willingness as discussed by the participants commands a lot of courage: "I also, have the courage to be vulnerable. I don't know if we even give ourselves that ability to be vulnerable right?"

\section{Improving teaching practice}

Opening up or having the courage to be vulnerable is experienced in the identification of the need to improve teaching practice in the first place. This is seen through subthemes of: the motivation for participating in the pilot of peer and selfassessment of teaching, the experiences of incorporating selfreflection as steps in the process, learning through observing others, and can result in the development of a community of support for teaching development in nursing education.

\section{Motivation to participate}

Participants identified that one motivating factor for engaging in this pilot was to receive a more rounded picture of their teaching abilities than simply relying on the student evaluations that make up the brunt of any teaching feedback that they receive. The importance of a forum in which peers could give and receive feedback regarding teaching practices 
was acknowledged to be an important motivator for participants who may not have thought to have asked for feedback from a colleague. When asked if she would have sought peer feedback about her teaching, a participant responded, "No, I don't think so. I don't really know that it was because I had ruled that [peer feedback] out, or I just wouldn't have known to have done that." Vulnerability, therefore, exists not only in the limited feedback that educators receive in the form of student evaluations but also in seeking out additional measures, such as assistance by a peer to improve teaching practice.

Participants saw the benefit of a process of peer and selfassessment of teaching that is specific to nursing education as a motivating factor to engage in the process:

I found this [the process] much more specialized because

[the peer observer] is an experienced teacher and she is also expert on the topics that I'm speaking to. So it's a much more personalized, tailored way to learn.

Along with a tailored approach, the participants appreciated a forum with an emphasis on providing support to colleagues as a means of easing feelings of vulnerability and allowing educators to focus on development and learn from their peers: "There is no performance evaluation per se attached to it [the process], it's really safe." The benefit of a tailored and discipline specific forum was also supported by the exploration of motivation for participation from an administrative perspective. A participant in an administrative role found a potential benefit of the engagement of educators in a process of peer and self-assessment to be the integration or normalization of processes of professional teaching development. This normalization could decrease feelings of vulnerability held around development or receiving feedback around teaching practices and reinforce the supportive developmental nature of peer and self-assessment:

It is not just about performance and competence [...], but that this is a continual crafting of an identity and a practice as a teacher I think is kind of significant.

\section{Self-reflection}

In the focus groups and interviews, participants who selfidentified as experienced educators saw self-reflection, as part of the process of peer and self-assessment, to be of benefit as a means of improving teaching practice. Discussions with these participants highlighted vulnerabilities around assumptions related to years of teaching experience and the need for ongoing teaching development.
There's a lot of assumptions when you've been teaching for a while that you don't need to develop any further. So doing the self-reflective piece was really insightful because, there's lots of things that I want to enhance and try, and continue to grow and develop in my teaching.

Participants who considered themselves novices had a different view of the steps of self-reflection recommended as part of the process cycle. Some participants noted that the amount of time to complete a self-reflective summary was burdensome and perhaps unnecessary. However, the learning that occurred for one novice educator who engaged in the full process cycle, including the completion of a written summary, was more fulsome and had a bigger impact on the participant's plans for future professional teaching development and the incorporation of the feedback received from her peer into her teaching practice, than for a participant who did not fully engage in the steps of selfreflection. This difference in perceptions related to self-reflection highlights the individual nature of engaging in professional teaching development and indicates that the depth of learning that could occur is dependent upon the level of engagement and commitment to the process. The following quote demonstrates the different levels that self-reflection can take:

I'm fairly self-reflective as a rule as well, but to actually articulate that in writing, it's a little more substantive, a little more challenging and then to share that with someone else, again it's kind of the public nature of that [...], it's pretty revealing, it's a lot of hard work though too.

Though there may have been some resistance to engaging in a written form of self-reflection, the benefit of self-reflection, in whatever form it took, outweighed any concerns held around the time that it took to complete. Some participants suggested that perhaps the steps of self-reflection could be more flexible for future iterations of peer and self-assessment cycles and rather than requiring a written summary, it could be a verbal discussion, point form notes, or whatever participants choose to do to best benefit their own learning. From the focus group discussions and interviews, it was clear that self-reflection as steps in the process of peer and self-assessment could not only help to identify learning needs but also work to ease feelings of vulnerability and fear associated with exposing individual teaching practices to peers. This in turn could lead to improved teaching practices and potentially benefit student learning.

\section{Community of support}

There was common agreement among participants that a clear benefit of engaging in a process of peer and self-assessment was the mutual learning that takes place by nature of observing others teach. 
This mutual learning was seen as important for teaching in nursing, where those tasked with educating nursing students are for the most part not formally trained to be teachers:

I think the other piece is you know, when you become an instructor whether it be academic or practice, I mean we all went to nursing school we didn't learn to be teachers.

So we all kind of just jumped in at some point and were expected to do a job that we weren't formally trained to do.

I think that it's nice to be able to go and watch each other and learn from what works.

Participants agreed that this mutuality could lead to the creation of a community of support for teaching development by sharing teaching practices, identifying teaching strengths, and creating trust among teaching colleagues:

I think it's actually helping develop the seasoned instructors but also helping people build an appreciation for what, what each colleague is bringing to the table.

Through the development of a supportive community, teaching spaces could be opened up, teaching expertise shared and any fears that are held by educators around teaching in new or different environments could be identified and addressed.

\section{Accountability and responsibility}

Despite the influence of feelings of vulnerability on most aspects of the process of peer and self-assessment of teaching, the continued commitment of those involved indicated a sense of accountability and responsibility that outweighed such vulnerabilities. Participant discussions highlighted a strong commitment to not only the undergraduate curriculum but also individual and team growth. In particular, participants recognized how engaging in processes such as peer and self-assessment of teaching was congruent with and supportive of the integrated curriculum and resulting teamoriented approach to teaching. "They see things in practice with students and then in a theory course and how they all relate so the curriculum absolutely asks us to do that."

While it was assumed during the development of the pilot process that the impetus for participating had a strong link to meeting professional development expectations as part of an educator's annual performance review (APR), the findings from the interviews and focus groups indicated that the rationale was less to do with APRs and more to do with being able to provide support to teaching colleagues and benefit student learning through quality teaching. "For me it was around building collegiality and engagement in our faculty, in our teaching team." Another participant indicated "there is a different emphasis in the teaching [...] the need to sustain the quality of the teaching but also help to foster development amongst our folks."

Commitment between partners was evident in continued involvement in the process cycle despite the time commitment involved. The participants who completed the full process cycle agreed that it demanded a large amount of time. When asked why one participant continued to be involved in the pilot despite the knowledge of how much time it would take, a commitment to her partner and the value she placed in her partner's ability to provide her with useful feedback outweighed the extra time required outside of her teaching commitments. Participants were clearly committed to their partners in this process:

Some are saying we're still working at it and this is four months into it and they're still working on pieces of it, I think that's a significant commitment to their own development and to their peer's development.

Commitment between partners and to providing support for the professional growth of peers was also clear in the desire to provide quality feedback. Participants spoke about the need to offer a balanced critique and the fine line that exists between offering an evaluation and providing objective feedback for the purposes of development:

I think she felt really positive on the feedback I was able to give her about all the wonderful things that she's doing and how impressed I was. That's not to say there wasn't areas to work on which I was able to share as well, but [...] I don't think she felt confident so I thought she, she might have felt like she was going to get a lot of tips and no accolades.

So it was maybe reaffirming for her.

The desire to provide quality feedback, however, led to feelings of vulnerability regarding participant's ability to reciprocate with equally valuable feedback to their partners.

\section{Discussion}

This qualitative descriptive study revealed that peer and selfassessment of teaching is a potentially beneficial teaching development tool for academic nursing educators. Educators involved in the pilot program and study indicated possible benefits to individual teaching practice, to team development, and to collegiality. Peer and self-assessment can be used in addition to student evaluations as a means of receiving feedback on teaching strengths and areas in need of focused development. Findings related to the need for trust between partners and benefits of a structured process, including the importance of the premeeting discussion for establishing trust and setting goals, are supported through findings of existing research and descriptive literature regarding varying 
processes of peer observation. ${ }^{18,19,24}$ In addition, potential benefits described by participants that result from making teaching practices public and engaging in discussions about teaching and learning, including improving teaching practices, mutual learning, and enhanced collegiality, are in line with the findings of previous studies. ${ }^{9,19,24}$ Unique from the findings of this study, based on the experiences of study participants, is the presence and impact of feelings of vulnerability on the entire process of peer and self-assessment.

Feelings of threat and anxiety related to being observed whether for developmental or for performance evaluation purposes are a common finding from existing peer assessment research literature, ${ }^{9,18,19,24,25}$ however, there are limited published data that refer to feelings of vulnerability, and the influence and meaning of vulnerability. Vulnerability is defined as susceptibility to attack, harm, emotional injury, or criticism. ${ }^{33}$ Participants of this study did not describe feeling threatened, attacked, or at risk of harm, rather the language of vulnerability was associated with digging deeper to understand more about individual teaching strengths and areas in need of development, sharing those feelings with a colleague, and then making individual teaching public by opening up the classroom to someone other than students. Understanding the impact that vulnerability can have on nursing educators at any step of the process is an important element of developing and successfully sustaining professional development processes such as peer and self-assessment of teaching.

Vulnerability associated with different forms of peer observation has greater representation in education research literature. Eisenbach and Curry ${ }^{34}$ wrote about the emotional reactions that they each had in relation to a peer-coaching partnership between educators in higher education. Their work echoes the feelings of vulnerability associated with being observed, vulnerability around asking for feedback regarding teaching practices, and questions concerning what the less experienced partner would have to offer to the relationship, similar to the feelings expressed by the participants of this study. ${ }^{34}$ What was different with the Eisenbach and Curry ${ }^{34}$ study was that each partner was from a different teaching faculty and this was felt to be an important element of a successful peer-coaching relationship to truly offer developmental feedback without the biases they saw associated with knowing the curriculum being observed. While the process of choosing and being observed by a teaching colleague was found to cause feelings of vulnerability, participants from the current study found a discipline or curriculum-specific process to be favorable and a benefit to their own professional development.
Huckaby $^{35}$ explored the vulnerabilities experienced by academic teaching staff involved as participants in education research. Participants were reluctant to share teaching stories and strategies due to the fear of the impact that this could have on their teaching positions..$^{35}$ In her work, Huckaby ${ }^{35}$ linked the fear and vulnerability experienced to the power relations between researcher and participant. Though feelings of vulnerability eased during the development of a trusting relationship, these feelings never fully went away but rather were interconnected and could fluctuate with power or vulnerability becoming more dominant over the other depending on what was occurring in the relationship. ${ }^{35}$ While the study by Huckaby ${ }^{35}$ was not related to peer assessment, the influence of power and vulnerability could be linked to the vulnerability felt by both peers in a peer assessment partnership. Power or courage around identifying the need for developmental support, and vulnerability around choosing a partner that could best benefit individual learning, along with feelings of vulnerability around being able to concurrently offer quality feedback and support, represents the connection of power and vulnerability held by both members of a peer and self-assessment partnership. While the intent of the process was to ensure that participants were equals, the fact that novice instructors looked to their more experienced colleagues as preferred partners, the desire by both partners to provide a best example of their teaching, and the underestimation by both peers as to what they would be able to reciprocate to their partners is also representative of this relationship. Understanding that both peers, no matter their experience level, can question their roles in a peer assessment partnership was important in creating the sense of equality that was a pivotal part of the philosophy of the project described in this article.

The nexus of power and vulnerability described by Huckaby ${ }^{35}$ could also be linked to the vulnerability experienced in the transition from an expert clinical practitioner to a novice educator as noted by study participants and supported in the literature through the work of Benner ${ }^{36}$ and McArthur-Rouse. ${ }^{37}$ Participants struggled with power and vulnerability within themselves in the identification of their teaching development needs and the creation and understanding of their individual teaching identities. To support and sustain a satisfied team of academic nursing educators, it is of great significance to understand what they could be feeling and experiencing. ${ }^{37}$ It is, therefore, pivotal that faculty administrators recognize that while teaching development is imperative, it is of equal importance to be aware of the courage that it takes for practitioners to admit that they require 
help in identifying and developing their teaching skills and identities. ${ }^{34,38}$ One of the elements of the model of peer and self-assessment of teaching developed for the pilot project that was of significant interest to the research team was the experiences of incorporating self-reflection as steps of the process. While self-reflection is noted as an important element of professional teaching development in processes of peer observation or assessment, $, 19,20,22,27,28$ the incorporation of actual steps of self-reflection and the emphasis on a final self-reflective summary by the partner at the receiving end of peer feedback provision for the sole purpose of development and not performance evaluation, is unique to this pilot project. A 2001 study by Bell ${ }^{39}$ discussed the development and implementation of a process cycle similar to the one developed for the project reported in this article, in that there was a distinct emphasis on self-reflective steps. Where the processes differ is in the underlying purpose of engaging in self-reflection. Unlike the project referred to in this article the focus was developmental and supportive in nature, whereas the model described by Bell ${ }^{39}$ has an underlying evaluative tone. While engagement in the process described by Bell ${ }^{39}$ results in professional teaching development, the process becomes evaluative when participants are required to submit self-reflections for review by a third-party educational developer. From the results of this study, self-reflection for the purposes of development can add to the potential gains and depth of learning of nursing educators. Maintaining flexibility and individuality in the form in which self-reflection occurs is an important element to sustain peer and self-assessment as a developmental process. Nursing faculties are known to encourage the use of self-reflection as a method of educational and professional growth for students; this same practice should be developed and applied to their own professional development. ${ }^{40}$ Participants of this study described that opening up their classrooms and making their teaching practices public to other teaching colleagues could bring teaching in nursing more into a public domain and could match it to the public nature of practice in clinical settings. The importance of the congruence between teaching practice to clinical nursing practice can also be said for the importance of engaging in self-reflection for professional teaching development along with clinical competence. It is a professional expectation that nurses engage in critical self-reflection as a part of the continuing competence requirements of professional regulatory bodies. ${ }^{3}$ Therefore, engaging in self-reflection throughout a professional development strategy, such as peer and selfassessment, can not only help individual nurses to identify teaching development needs but also help to meet yearly professional practice requirements. ${ }^{3}$ While some participants of this study indicated that the self-reflective steps were perhaps not necessary, the experiences of those that took part and embraced self-reflection were richer and more meaningful than for those that did not. The full circle model of peer and self-assessment developed for this pilot begins and ends with the individual seeking feedback on teaching practices: selfreflection can be viewed in the same manner in that individual nurse educators can expect to gain from the experience equal to what they put in. ${ }^{41}$ Gaining the courage to open up to the vulnerability associated with participating in peer and selfassessment of teaching is reflective of the work of Palmer ${ }^{41}$ who suggested that before educators can be effective at their jobs and have a positive impact on the learning of students, they need to come to terms with the ups and downs that are associated with teaching, and to do so, they must be willing to look inside themselves to understand their own identities. Self-reflection is one means of identifying and understanding an educator's strengths and areas that could benefit from the supportive feedback of a colleague. ${ }^{42,43}$

One final important factor to consider from the findings of this descriptive study is the influence that the curricular structure of the study environment had on the experiences of participants in this peer and self-assessment pilot project. Participants showed a strong commitment to the integrative structure of the undergraduate nursing curriculum. While vulnerability was noted throughout the process, participants understood the importance of gaining the courage to explore their own needs and vulnerabilities, share those with a trusted colleague, and work to ensure not only their own independent growth but also the growth of their teaching colleagues as a means of ultimately impacting the quality of teaching and learning for their students. Educational reform is a topic that has been discussed at length and there have been numerous calls for faculties of nursing education to innovate and embrace change as a means of preparing new nurses for practice in evolving and demanding health care environments. ${ }^{44,45}$ The adoption and embracing of a curriculum that seeks to meet such calls may be one reason why participants in the study associated with this article continue to show interest and dedicate time to be involved despite the demands of their teaching schedules. The vision of the university in which the study took place is to aim for excellence in research as well as teaching and learning and therefore the dedication and commitment of faculty members to improve the teaching abilities of themselves and their colleagues is also in line with the goals of the greater university community. ${ }^{46}$ The findings of this study not only support the awareness and need for more support for teaching development, but also the experiences of participants will add to the limited amount 
of published nursing education research literature regarding processes that could benefit professional growth, and the quality of education delivered to students.

\section{Limitations and recommendations}

This research is limited in that the findings are contextual and the sample is small. Data saturation may not have been reached. However, the dense description allows other researchers and educators to transfer the findings reported in this article to their contexts.

Future research aimed at gathering data from a larger number of faculty members who have completed the full process cycle in both roles would add to the breadth and depth of the data and provide greater insight into the experiences of nursing educators involved in peer and self-assessment of teaching. In addition, a potential area for future research would be to look at the longitudinal benefits of incorporating a system of peer and self-assessment of teaching into the professional development strategy of the study institution as well as to look at the impact of engaging in this process on outcomes such as staff job satisfaction, retention, and student learning. Looking at longer-term outcomes would address a significant literature gap related to a lack of longitudinal studies.

Faculties who choose to adopt similar processes of peer and self-assessment of teaching must consider ways to sustain such initiatives. The findings of this study provide preliminary evidence-based knowledge around the importance of adopting a tailored approach to teaching development and involving key stakeholders from the grass roots. The full circle model described in this article should be tested for sustainability.

\section{Conclusion}

This study provides support for the development and integration of tailored processes of professional teaching development with a focus on self-reflection and peer feedback. Feelings of vulnerability can surface around all elements of participating in a process of peer and self-assessment, can be experienced by both partners, and demand a significant amount of courage to overcome. Having the courage to be vulnerable and to open up and expose individual teaching practices and vulnerabilities and establish trust with a teaching colleague can result in mutual learning and benefit both individual and team growth. Nonevaluative methods of receiving feedback on teaching practices, such as peer and self-assessment, could help to provide educators with a more rounded picture of their teaching strengths and areas in need of development than simply relying on the heavily weighted student evaluations of teaching. Providing educators in academic nursing faculties with additional tools, and creating a supportive collegial environment in which to learn and grow, is an important element of working toward maintaining a committed teaching team. There continues to be a shortage of qualified nurses, and working to provide support and encouraging the ongoing development of nursing educators is a key element of enhancing the quality of education provided to students, and ultimately ensuring the continued graduation of a sustainable professional nursing workforce.

\section{Acknowledgments}

The authors would like to thank the members of the faculty of nursing as this study could not have been completed without their commitment and cooperation.

\section{Disclosure}

The authors report no conflicts of interest in this work.

\section{References}

1. Berk RA, Naumann PL, Appling SE. Beyond student ratings: peer observation of classroom and clinical teaching. Int J Nurs Educ Scholarsh. 2004;1(1):1-26.

2. Emery CR, Kramer TR, Tian RG. Return to academic standards: a critique of student evaluations and teaching effectiveness. Qual Assur Educ. 2003;11(1):37-46.

3. College and Association of Registered Nurses of Alberta. Practice Standards for Regulated Members. College and Association of Registered Nurses of Alberta; 2013. Available from: http://www.nurses. ab.ca/content/dam/carna/pdfs/DocumentList/Standards/PracticeStandards_CNA_Ethics_2008.pdf. Accessed August 28, 2016.

4. Sarmiento TP, Spence Laschinger HK, Iwasiw C. Nurse educators' workplace empowerment, burnout, and job satisfaction: testing Kanter's theory. J Adv Nurs. 2004;46(2):134-143.

5. Tanner C. What are our priorities? Addressing the looming shortage of nursing faculty. $J$ Nurs Educ. 2005;44(6):247-248.

6. Brown B, Ward-Griffin C. The use of peer evaluation in promoting nursing faculty teaching effectiveness: a review of the literature. Nurse Educ Today. 1994;14(4):299-305.

7. Gosling D. Models of Peer Observation of Teaching. Generic Centre: Learning and Teaching Support Network; 2002. Available from: https:// www.researchgate.net/publication/267687499_Models_of_Peer_Observation_of_Teaching. Accessed January 15, 2016.

8. Tighe SM, Bradshaw C. Peer-supported review of teaching: making the grade in midwifery and nursing education. Nurse Educ Today. 2013;33(11):1347-1351.

9. Costello J, Pateman B, Pusey H, Longshaw K. Peer review of classroom teaching: an interim report. Nurse Educ Today. 2001;21(6):444-454.

10. Sandelowski M. Whatever happened to qualitative description? Res Nurs Health. 2000;23(4):334-340.

11. Diekelmann N. Class evaluations: creating new student partnerships in support of innovation. J Nurs Educ. 2004;43(10):436-439.

12. Hessler K, Humphreys J. Student evaluations: advice for novice faculty. J Nurs Educ. 2008;47(4):187-189.

13. Wellein MG, Ragucci KR, Lapointe M. A peer review process for classroom teaching. Am J Pharm Educ. 2009;73(5):79.

14. Bernstein DJ, Jonson J, Smith K. An examination of the implementation of peer review of teaching. New Dir Teach Learn. 2000;2000(83):73-86. 
15. Keig L. Formative peer review of teaching: attitudes of faculty at liberal arts colleges toward colleague assessment. J Person Eval Educ. 2000;14(1):67-87.

16. Toth $\mathrm{KE}, \mathrm{McKey} \mathrm{CA}$. Identifying the potential organizational impact of an educational peer review program. Int J Acad Dev. 2010;15(1): 73-83.

17. Turner L. Discussion of a project on peer evaluation in the faculty of nursing, University of Toronto, Canada. J Adv Nurs. 1978;3:457-473.

18. Bennett PN, Parker S, Smigiel H. Paired peer review of university classroom teaching in a school of nursing and midwifery. Nurse Educ Today. 2012;32(6):665-668.

19. Carroll C, O'Loughlin D. Peer observation of teaching: enhancing academic engagement for new participants. Innovat Educ Teach Int. 2014;15(4):446-456.

20. O’Keefe M, Lecouteur A, Miller J, McGowan U. The colleague development program: a multidisciplinary program of peer observation partnerships. Med Teach. 2009;31(12):1060-1065.

21. Martsolf DS, Dieckman BC, Cartechine KA, Starr PJ, Wolf L, Anaya ER. Peer review of teaching: instituting a program in a college of nursing. J Nurs Educ. 1999;38(7):326-332.

22. Mager DR, Kazer MW, Conelius J, et al. Development, implementation and evaluation of a peer review of teaching (PRoT) initiative in nursing education. Int J Nurs Educ Scholarsh. 2014;11(1):1-8.

23. Burrows T, Findlay N, Killen C, Dempsey SE, Hunter S. Using nominal group technique to develop a consensus derived model for peer review of teaching across a multi-school faculty. J Univ Teach Learn Pract. 2011;8(2):1-9.

24. McLeod P, Steinert Y, Capek R, et al. Peer review: an effective approach to cultivating lecturing virtuosity. Med Teach. 2012;35(4):e1046-e1051.

25. Pattison AT, Sherwood M, Lumsden CJ, Gale A, Markides M. Foundation observation of teaching project: a developmental model of peer observation of teaching. Med Teach. 2012;34:e136-e142.

26. Chism N. Peer Review of Teaching: A Source Book. 2nd ed. Bolton, MA: Anker Publishing Company; 2007.

27. Finn K, Chiappa V, Puig A, Hunt D. How to become a better clinical teacher: a collaborative process. Med Teach. 2011;33:151-155.

28. Gusic M, Hageman H, Zenni E. Peer review: a tool to enhance clinical teaching. Clin Teach. 2013;10(5):287-290.

29. Rosenau P, Watson L, Vye-Rogers L, Dobbs M. Educating for complexity in nursing practice: a baccalaureate curriculum innovation. Qual Adv Nurs Educ. 2015;1(3):1-14.

30. Capra F. The Hidden Connections: A Science for Sustainable Living. New York: Anchor; 2004
31. Hsieh H, Shannon SE. Three approaches to qualitative content analysis. Qual Health Res. 2005;15(9):1277-1288.

32. Booth R. Happiness, stress, a bit of vulgarity, and lots of discursive conversation: a pilot study examining nursing students' tweets about nursing education posted to Twitter. Nurse Educ Today. 2015;35(2):322-327.

33. Vulnerability. [webpage on the Internet]. American Heritage ${ }^{\circledR}$ Dictionary of the English Language. Fifth ed. 2011. Available from: http:// thefreedictionary.com/vulnerability. Accessed April 29, 2016.

34. Eisenbach R, Curry RR. The emotional reaction to classroom visitation and peer coaching. J Manag Educ. 1999;23(4):416-427.

35. Huckaby MF. Researcher/researched: relations of vulnerability/relations of power. Int J Qual Stud Educ. 2011;24(2):165-183.

36. Benner P. From Novice to Expert, Excellence and Power in Clinical Nursing Practice. Menlo Park, CA: Addison-Wesley Publishing Company; 1984:307.

37. McArthur-Rouse FJ. From expert to novice: an exploration of the experiences of new academic staff to a department of adult nursing studies. Nurse Educ Today. 2008;28(4):401-408.

38. Cangelosi PR, Crocker S, Sorrell JM. Expert to novice: clinicians learning new roles as clinical nurse educators. Nurs Educ Perspect. 2009;30(6):367-371.

39. Bell M. Supported reflective practice: a programme of peer observation and feedback for academic teaching development. Int J Acad Dev. 2001;6(1):29-39.

40. Drevdahl DJ, Stackman RW, Purdy JM, Louie BY. Merging reflective inquiry and self-study as a framework for enhancing the scholarship of teaching. J Nurs Educ. 2002;41(9):413-419.

41. Palmer PJ. The Courage to Teach: Exploring the Inner Landscape of a Teacher's Life. San Francisco: John Wiley \& Sons; 2010.

42. Goldstein J, Noguera PA. A thoughtful approach to teacher evaluation. Educ Leader. 2006;63(6):31.

43. Kelchtermans G. Who I am in how I teach is the message: self-understanding, vulnerability and reflection. Teachers Teach Theor Pract. 2009;15(2):257-272.

44. Benner P, Sutphen M, Leonard V, Day L. Educating Nurses: A Call for Radical Transformation. Vol. 15. San Francisco: John Wiley \& Sons; 2009.

45. Forbes MO, Hickey MT. Curriculum reform in baccalaureate nursing education: review of the literature. Int J Nurs Educ Scholarsh. 2009;6(1):Article27, Epub 2009 Aug 14

46. University of Calgary. Eyes High: University of Calgary 2011 Vision and Strategy. 2011. Available from: https://issuu.com/devoff/docs/ eyes_high/1?e=1838941/10815898. Accessed January 4, 2017.
Nursing: Research and Reviews

\section{Publish your work in this journal}

Nursing: Research and Reviews is an international, peer-reviewed, open access journal publishing original research, reports, reviews and commentaries on all aspects of nursing and patient care. These include patient education and counseling, ethics, management and organizational issues, diagnostics and prescribing, health outcomes, economics and

\section{Dovepress}

resource management, improving patient safety in all settings. The manuscript management system is completely online and includes a very quick and fair peer-review system. Visit http://www.dovepress. $\mathrm{com} /$ testimonials.php to read real quotes from published authors. 